\title{
EFFECT OF QUENCH ENVIRONMENT ON THE CONVERSION COATINGS ON MAGNESIUM ALLOY AZ91
}

\author{
Barbora Ševčíková1, Stanislava Fintová2, \\ Jaromír Wassebauer ${ }^{1}$, Jakub Tkacz ${ }^{1}$
}

\begin{abstract}
${ }^{1}$ Materials research Centre by Faculty of Chemistry, Brno University of Technology, 61200 Brno, Purkyňova 464/118, 60200 Brno, Czech Republic

${ }^{2}$ Institute of Physics of Materials of the Academy of Sciences of the Czech Republic, v.v.i., Žižkova 22, 61662 Brno, Czech Republic
\end{abstract}

\begin{abstract}
ŠEVČÍKOVÁ BARBORA, FINTOVÁ STANISLAVA, WASSEBAUER JAROMÍR, TKACZ JAKUB. 2018. Effect of Quench Environment on the Conversion Coatings on Magnesium Alloy Az91. Acta Universitatis Agriculturae et Silviculturae Mendelianae Brunensis, 66(1): 0203-0210.

The aim of the study is to achieve fine microstructure of AZ91, due to the optimized heat treatment processes, which can be easily coated with a normal conversion process as phosphating. Determination of the influence of the AZ91 microstructure, mainly precipitates which are created using different cooling media during the heat treatment and definition of the best heat treatment process parameters are the main experimental sections of the work. The structure of the samples heat treated under different conditions was subsequently compared with the structure of the as cast state of AZ91. The morphology of the conversion coating was studied by scanning electron microscopy (SEM) and amount of individual elements in the deposited coating was determined by EDS analysis.
\end{abstract}

Keywords: magnesium alloys; AZ91; conversion coating, precipitation hardening, cryogenic treatment; EDS analysis; SEM mapping

\section{INTRODUCTION}

Magnesium and its alloys utilization expand today to automotive, aerospace, consume and military industry (Luo, 2013). Increasing consumption of this nonferrous metal is predetermination by a combination of good mechanical properties, very low specific weight (about $25 \%$ lower in comparison with ordinary steel), creep resistance, good machinability and castability (Gray and Luan, 2002; Housh and Mikucki, 1990; Mordike and Ebert, 1990). The advantage of magnesium alloys usage is a significant reduction of operation costs and the $\mathrm{CO}_{2}$ emissions in the air (lower energy intensity of production).

The main negative aspects of magnesium alloys are high shrinkage during solidification and high chemical reactivity with the air atmosphere (ASM,
1999). With the aim to improve the corrosion resistivity of these alloys is the topic to find efficient technologies to increase magnesium corrosion resistance (Cao et al., 2016), processing of new multicomponent magnesium-based alloys (Shaozhen et al., 2017), heat (Westengen et al., 2016) and thermo-mechanical (Preciad et al., 2017; Wang et al., 2006) treatment and surface coating (Wang et al., 2006; Zhao et al., 2006). The fact that the environmental criteria continue to be stricter contributes to the continuously limited selection of appropriate chemicals applicable to the active $\mathrm{Mg}$ surface protection (Zhao et al., 2006).

Therefore, the emphasis on rapid development in the field of the conversion coating is observed (Pommiers et al., 2014; Barranco et al., 2010). 
Due to the wide range of application in recent industrial use is the most frequently investigated $\mathrm{Mg}$ alloy is AZ91. From the coatability point of view, AZ91 alloy disadvantage is that it contains quite a high amount of $\beta$ intermetallic phase forming a galvanic connection in the phase interface (Singh et al., 2015). This leads to accelerated corrosion and in most cases, it also impairs a nucleation phase of the protective coating (van Phuong et al., 2013). For this reason, heat treatment is often applied to magnesium alloys in order to create the finest and the most uniform phase distribution (these treatments were primarily developed to improve mechanical properties). In the case of $\mathrm{Mg}$ alloys prepared by low-pressure casting is usually used the T6 processing, consisting of solution heating which is followed by quenching and artificial aging to create uniform precipitates distribution (ASM, 1999).

This paper analysis combination of modified T6 heat treatment (Westengen et al., 2016; Preciad et al., 2017; Wang et al., 2006) and surface treatment (Pommiers et al., 2014; Barranco et al., 2010; Singh et al., 2015; Zhao et al., 2008) of AZ91 to achieve better coatability.

\section{MATERIALS AND METHODS}

\section{Material}

As the test material was selected conventional AZ91D alloy cast by high-pressure casting (80/140 MPa) on UBE HVSC 350 machine. The composition of the alloy was verified by an optical emission spectrometer with glow discharge Spectrumat GDS 750 and is in agreement with EN 1753 standard. Refinement and uniform distribution of precipitates in material structure due to the applied heat treatment was verified by hardness measurement on LECO AMH hardness tester with applied loads of 2 and $0.025 \mathrm{~kg}$.

The microstructure of AZ91D heat treated specimens, was evaluated on the metallographic light optical microscope (LM) Zeiss Axio Observer Zml. Metallographic preparation consisted of mechanical grinding successively to 1200 grit abrasive paper, followed with polishing with $1 \mu \mathrm{m}$ diamond paste and etching in a picral solution (10 $\mathrm{ml}$ acetic acid, $10 \mathrm{ml}$ ethanol, $70 \mathrm{ml}$ distilled water and $10 \mathrm{ml}$ picric acid).

\section{Heat Treatment}

AZ91D cast structure homogenization and refinement was carried out by T6 heat treatment consisting of three steps: solution heating, quenching at various media and artificial aging. Solution heating was performed at the temperature of $413{ }^{\circ} \mathrm{C}$ for 16 hours. From this temperature, the samples were quenched to three different media-air, water at room temperature and liquid nitrogen. Subsequently were the samples artificially aged at the temperature of $168{ }^{\circ} \mathrm{C}$ for 16 hours. Individual heat treatment processes are listed in Tab. I (ASM, 1999).

Phosphate-permanganate treatment, (Pommiers et al., 2014), was used for specimens coating. The cast and heat treated AZ91D specimens were cut into specimens with dimensions of $10 \mathrm{~mm} \times 10 \mathrm{~mm} \times 2 \mathrm{~mm}$. Specimens were ground with 1200 grit abrasive papers and degreased in acetone. Prepared samples were immersed into the phosphating bath with defined composition (Tab. II) for a period of 5, 10 and 15 minutes. Mechanism of formation of the phosphatepermanganate coating is described with equations (Eq. 1-3). The chemical reactions between the oxidized base metal $\mathrm{Mg}$ with $\mathrm{Mn}$ (VII) acting as oxidant and the dihydrogenphosphate acting as a buffer is described with reaction 2 (Eq. 2). The reduction of $\mathrm{Mn}$ (VII) consume the ionts responsible for the bath $\mathrm{pH}$ increase, therefore the crystallization of solid species occurs. Below $\mathrm{pH}=3$ non-compact surface layer is formed and over $\mathrm{pH}=5$ the growth of the coating is to slow. Under optimal operating condition of the coating preparation (Tab. II), the coating is formed with dihrogenphosphate and of other $\mathrm{Mg}$ and Mn oxi-hydroxides (Eq. 3) (Zhao et al., 2008).

I: Applied heat treatment processes to AZ91D alloy

\begin{tabular}{lccc}
\hline \multicolumn{1}{c}{ Abbreviation } & Solution Heating & Quenching Medium & Artificial Aging \\
\hline AC (as cast) & - - & - - & -- \\
T6 & $413^{\circ} \mathrm{C}, 16$ hours & air & $168{ }^{\circ} \mathrm{C}, 16$ hours \\
H20 & $413^{\circ} \mathrm{C}, 16$ hours & water at room T & $168^{\circ} \mathrm{C}, 16$ hours \\
N2 & $413^{\circ} \mathrm{C}, 16$ hours & liquid nitrogen & $168^{\circ} \mathrm{C}, 16$ hours \\
\hline
\end{tabular}

Coating preparation and analysis

II: Chemical composition of the bath for coating

\begin{tabular}{cccc}
\hline Treatment & Bath composition & Content (g/L) & Operating condition \\
\hline $\begin{array}{c}\text { phosphate-permanganate } \\
\text { Zhao et al., 2006 }\end{array}$ & $\mathrm{NaH}_{2} \mathrm{PO}_{4} \cdot \mathrm{H}_{2} \mathrm{O}$ & 150 & $60^{\circ} \mathrm{C}$ \\
$\mathrm{KMnO} 4$ & 40 & $\mathrm{pH} 3-3.5$ \\
$5-15 \mathrm{~min}$ & \\
\hline
\end{tabular}




$$
2 \mathrm{MnO}_{4}^{-}+3 \mathrm{Mg}+8 \mathrm{H}_{\mathrm{aq}}^{+} \leftrightarrow 2 \mathrm{MnO}_{2}(\mathrm{~s})+3 \mathrm{Mg}^{2+}+4 \mathrm{H}_{2} \mathrm{O}
$$

$2 \mathrm{NaH}_{2} \mathrm{PO}_{4} \cdot \mathrm{H}_{2} \mathrm{O}+3 \mathrm{Mg}^{2+} \leftrightarrow \mathrm{Mg}_{3}\left(\mathrm{PO}_{4}\right)_{2}(\mathrm{~s})_{+}$

$+2 \mathrm{NaOH}+3 \mathrm{H}_{2}(g)$

$$
\mathrm{Mg}^{2+}+\mathrm{O}_{\text {(production in picking bath) }}^{2-} \leftrightarrow \quad \mathrm{MgO}(\mathrm{s})
$$

The morphology of the conversion coating was analyzed with a scanning electron microscope JEOL JSM-7600F (SEM). The same microscope was used to investigate the influence of heat treatment on the element distribution by energy-dispersive $\mathrm{X}$-ray spectroscopy (EDS) the elemental analysis of the new formed phosphate-permanganate surface was evaluated. The thickness of the prepared phosphate-permanganate coating was measured using thickness meter Elcometr 456.

\section{RESULTS AND DISCUSSIONS}

\section{Material}

Due to the applied solution heat treatment better dissolution of the eutectic, consisting of a substitutional solid solution of aluminum in magnesium with intermetallic $\beta$ phase $\left(\mathrm{Al}_{12} \mathrm{Mg}_{17}\right)$ bounded by precipitates, was achieved comparing to the as cast samples (Fig. 1, A). With subsequent artificial aging resp. precipitation hardening was received a more uniform distribution of precipitates along grain boundaries. In the case of free cooling (on air) from the temperature of $413^{\circ} \mathrm{C}$ (Fig. 1, B) is this phase more noticeable than at higher cooling rate and forms more robust regularly distributed clusters. When quenching to water or to nitrogen was performed, the grain refinement occurred. At the grain borders nuclei precipitate with a higher content of the dissolved phase $\beta$ than in the matrix (Fig. 1, C and D). In the case of AZ91D quenching to nitrogen (Fig. 1, D) was the temperature change so rapid that dendritic structure was characteristic for the treated material. The dendritic structure and different crystal orientations can be presumed as an initiation site for the growth of the cover coating. The dissolution of eutectic and precipitates of $\beta$ phase during artificially aging leads to precipitation of supersaturated solid solution and to formation of Guinier-Preston zones (phase $\theta$ ). These newly formed areas are coherent with the matrix and therefore are not observable by optical microscope (Yong et al., 2012). The dissolution of the $\beta$ phase is noticeable from SEM mapping of elements distribution (Fig. 2, A-D).

\section{Hardness testing}

The presence of $\theta$ phase can be confirmed with a local increase in micro hardness HV0.025 measured for samples quenched to water and nitrogen (Tab. III). The lower local hardness HV0.025 of not hardened samples (Tab. II, AC) can be explained with the lower mechanical properties of the solid solution (not hardened area) creating AZ91 structure. The slightly lower hardness of samples quenched to nitrogen (N2) in comparison with samples quenched to water (H20) is caused by the very low thermal conductivity of liquid nitrogen $(3.9 \times 10-4 \mathrm{~W} / \mathrm{mK})$ which decelerate the solid solution saturation of matrix (Amini et al., 2014).

The differences in the obtained values resulted from the local microstructure of the processed materials (grain boundaries, intermetallic phases and also precipitates created during the heat treatment). Higher values of microhardness (HV0.025) estimated for T6-water and T6-nitrogen processed materials compared to the AC and T6-air corresponds to the precipitation hardening due to a lot of small precipitates created in the solid solution grains during the processing, Tab. III. Microhardness testing (HV0.025) was performed with the aim to reveal local microstructural properties, while hardness testing (HV2) was performed to characterize the material as bulk. Hardness testing performed using $2 \mathrm{~kg}$ load ignore material local microstructural heterogeneity. As a result, similar values of hardness were measured for all the tested materials. Large areas of eutectic and present phases in AC and T6-air materials balanced the strengthening effect of precipitate hardening taking the place in T6-water and T6-nitrogen materials.

\section{Coatings characterization}

The influence of heat treatment to better coatability of AZ91D was analyzed with electron microscopy analysis of coated specimens (Fig. 3). The growth mechanism of coatings is represented through the documentation of coating surface of specimens treated for 5,10 and 15 minutes due to the immersion into the coating bath. The biggest difference between prepared coatings can be seen in compactness of the coating, especially for specimens heat treated at higher cooling rates (water and nitrogen, Fig. 2). The coating's thickness in the case of 15 minutes treated samples, was determined with the thickness meter and the determined value was in a range of 7-10 micrometers.

III: Samples hardness for different quenching mediums

\begin{tabular}{lcccc}
\hline \multicolumn{1}{c}{ Hardness } & AC & T6-air & T6-water & T6-nitrogen \\
\hline HV2 & $83 \pm 4$ & $85 \pm 3$ & $91 \pm 3$ & $81 \pm 4$ \\
HV0.025 & $59 \pm 4$ & $76 \pm 5$ & $101 \pm 7$ & $90 \pm 7$ \\
\hline
\end{tabular}



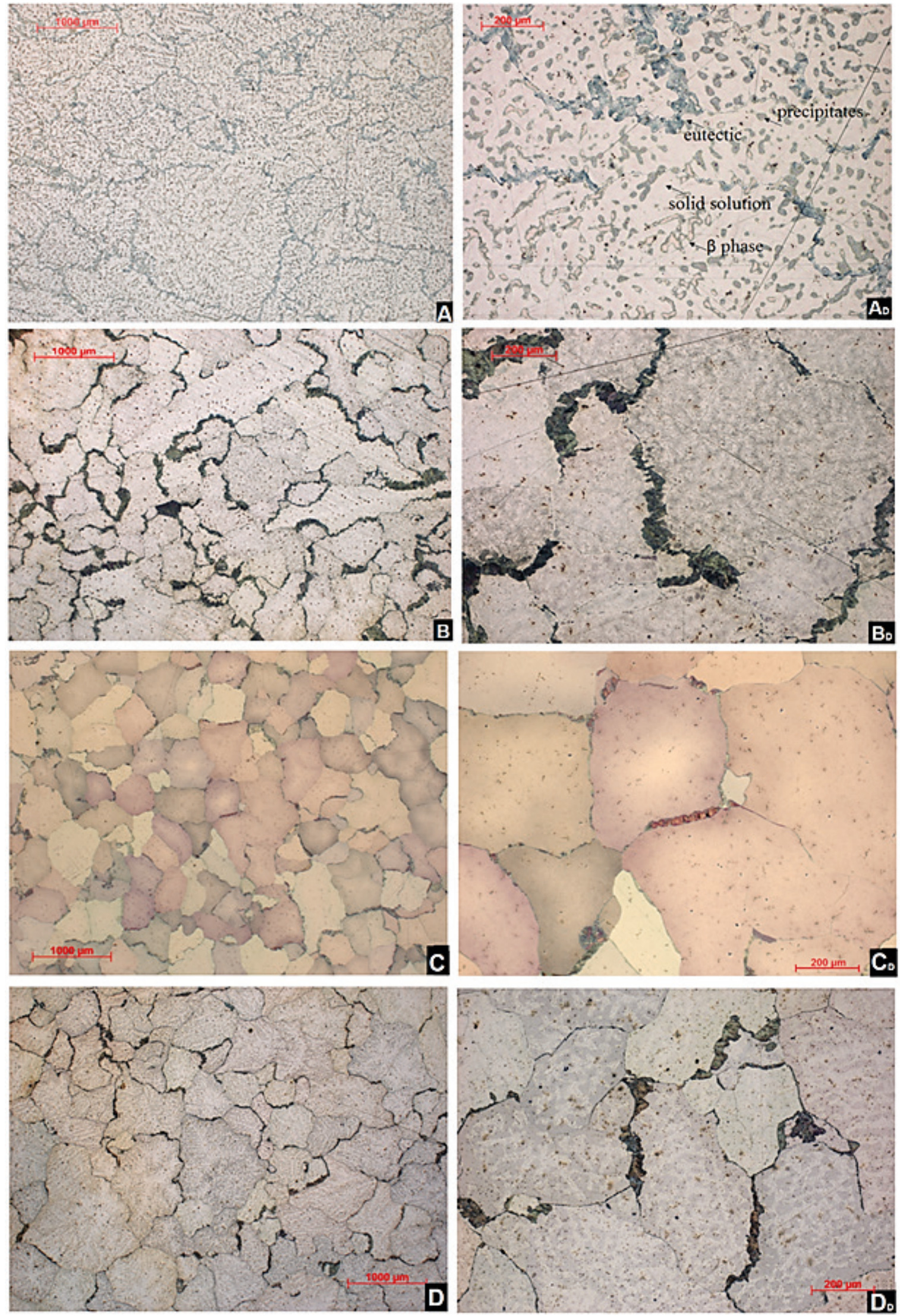

1: LM micrographs of AZ91 samples after etching in picral etchant (A) as cast, detail (B) air cooled, detail (C) water quenched, detail and (D) liquid nitrogen quenched, detail 
The presence of intermetallic $\beta$ phase $\left(\mathrm{Al}_{12} \mathrm{Mg}_{17}\right)$ seems to have an influence on the conversion coating preparation. In the case of specimens containing larger intermetallic particles (as cast state and alloy quenched on air) coating cracking in localized areas was observed, for all the coating times (Fig. 2, A and B). This localized areas seems to be adequate to the regions of higher content of $\mathrm{Al}$ present in the material structure mainly in the form of intermetallic $\beta$ phase $\left(\mathrm{Al}_{12} \mathrm{Mg}_{17}\right)$, (Fig 2, A,B). On the other hand, the coating prepared on specimens with more uniform chemical composition due to the applied heat treatment, including quenching to the water or liquid nitrogen, seems to be uniform and compact, (Fig. 3, C and D).

EDS analysis of the coatings surface (Fig. 4) was performed with the aim to characterize the coverage of specimens surface. An apparent decrease of $\mathrm{Mg}$ content and an increase of $\mathrm{O}$ content on the coating surface depending on the phosphating time was noticed for all the treated material states. This trend indicates on the growth of the coating (better coverage of surface) with increasing coating time. The formation of the coating can be derived from oxygen content (Eq. 2). Higher content of oxygen in the case of $\mathrm{T} 6$ treated or untreated samples is caused with the presence of inhomogeneities in substrates such as intermetallic particles or eutectics (Fig. 2, $\mathrm{A}$ and $\mathrm{B})$. These inhomogeneities act as nucleation areas and the coating grows there preferably upon formation of large phosphate crystal (Fig. 3, $\mathrm{A}_{15}$ ). The speed of the quenching seems to be irrelevant for this phenomena. The samples cooled slowly and rapidly shows the same trends (Fig. 4).
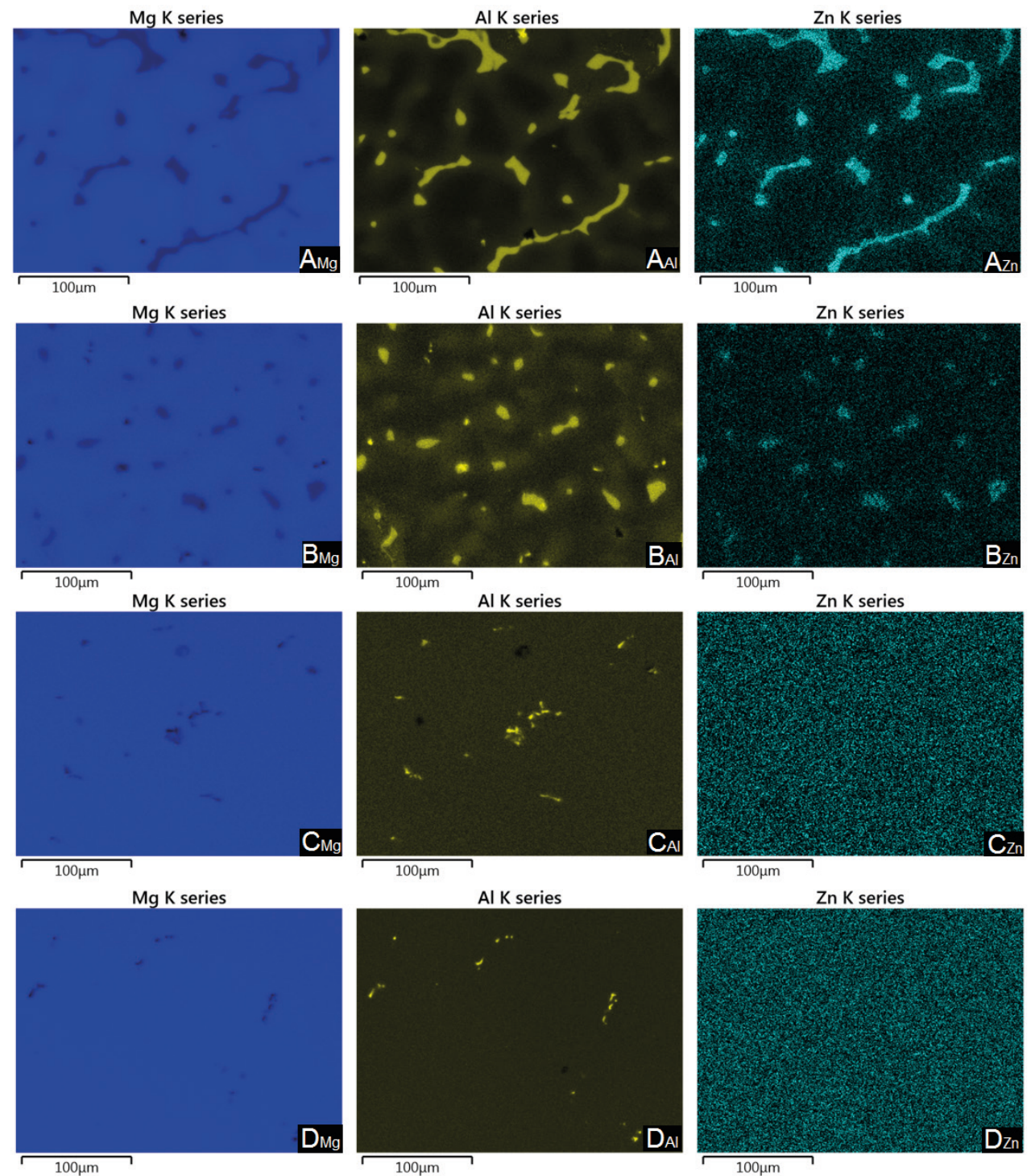

2: SEM mapping for main elements of AZ91 (Mg-magnesium, Al-aluminium and Zn-zinc) of samples (A) as cast, (B) air cooled, (C) water quenched and (D) nitrogen quenched, EDS SEM 


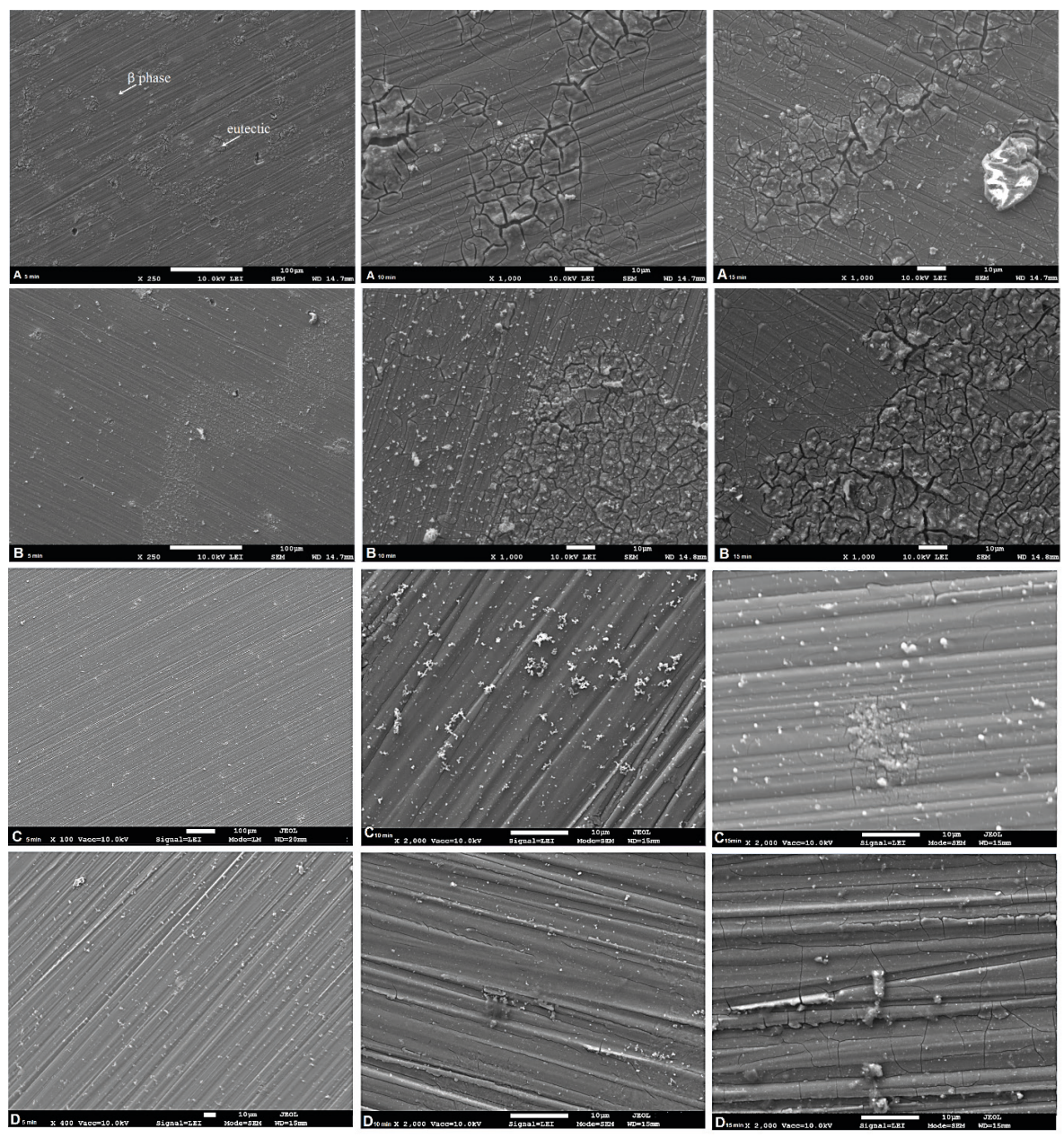

3: Growth of phosphate coating on the alloy AZ91 as-cast (A) and T6 heat treated (B), (C) water, (D) liquid nitrogen shown for the time of immersion 5, 10 and 15 minutes.

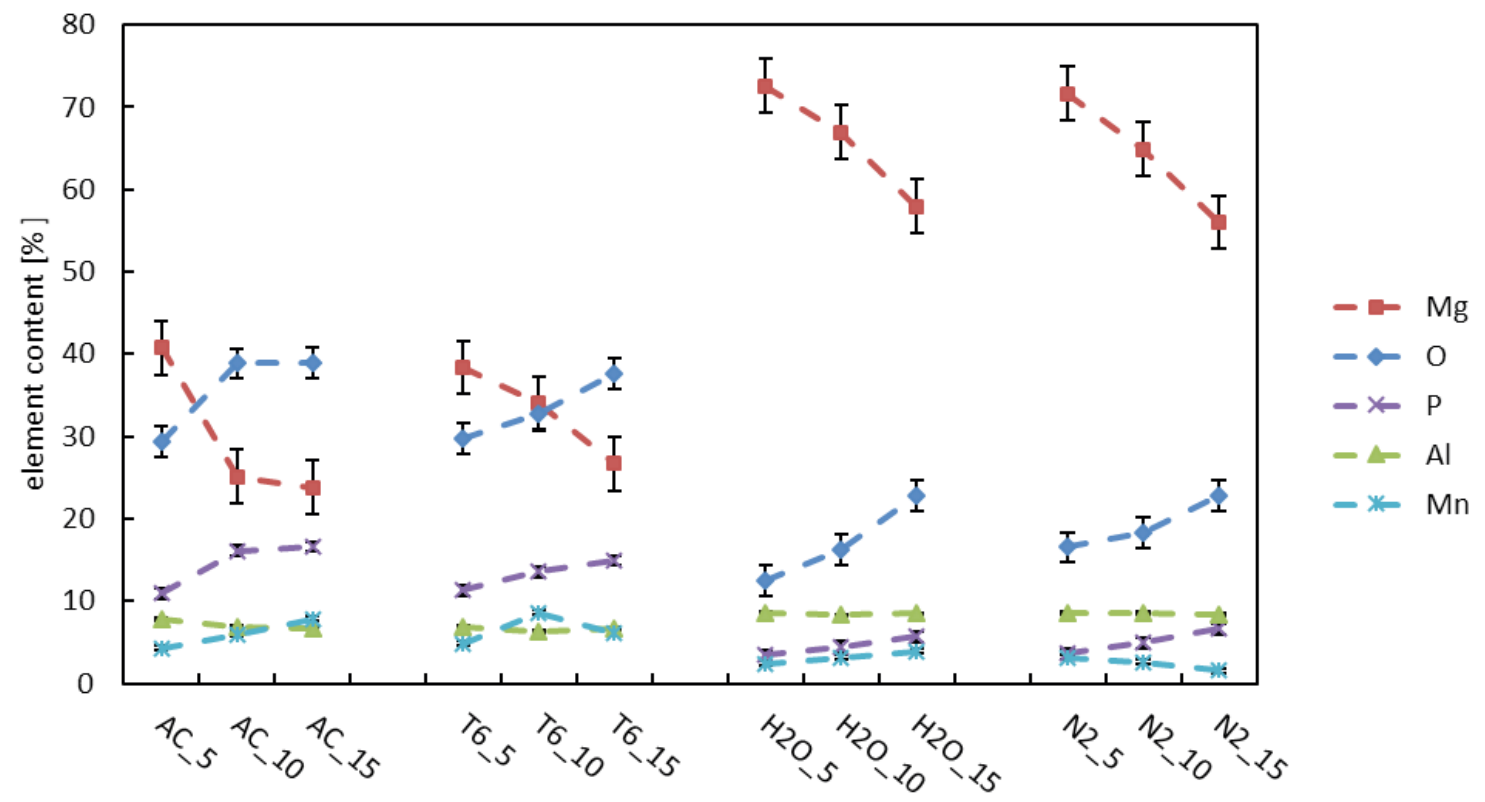

4: Results of EDS analysis sorted by cooling medium. AC-As cast, T6-air cooled, H2O-quenched to water, N2-quenched to liquid nitrogen. 


\section{CONCLUSION}

Dissolution of the $\beta$ phase by solution heating and subsequent re-precipitation during the artificial aging is confirmed for all kind of the used cooling media (air, water, liquid nitrogen). Material cooled in the nitrogen consisted of the finer and more homogenous structure comparing to the cast state of the material.

Hardness HV2 was comparable for all the material states, while small differences in local microhardness HV0.25 increase for rapidly quenched samples were observed.

A coating prepared on as cast material and material cooled on air were not uniform and cracks in areas corresponding to the presence of intermetallic $\beta$ phase $\left(\mathrm{Al}_{12} \mathrm{Mg}_{17}\right)$ in the material structure were observed.

The samples quenched to water respectively to liquid nitrogen exhibit more uniform coverage with the conversion coating comparing to the as cast state and material cooled on air.

From EDS analyses and evaluation of coating structure by electron microscopy is not visible any significant improvement in the coverage uniformity or element content by usage of liquid nitrogen as a quenching medium in comparison with usage the water as quenching medium.

\section{Acknowledgments}

This work was supported by the project "Materials Research Centre at FCH BUT-Sustainability and Development", REG LO1211, with financial support from National Programme for Sustainability I (Ministry of Education, Youth and Sports), Czech Republic.

\section{REFERENCES}

AMINI, K., AKHBARIZADEH, A. andJAVADPOUR, S. 2014. Investigating the effect of quench environment and deep cryogenic treatment on the wear behavior of AZ91. Materials and Design, 54: 154-160.

ASM. 1999. Magnesium and magnesium alloys. ASM Speciality Handbook Series. Materials Park, OH: ASM International.

ASTM. 2013. Standard Practice for Codification of Certain Nonferrous Metals and Alloys, Cast and Wrought. ASTM B275-13. West Conshohocken, PA: ASTM.

BARRANCO, V. et al. 2010. Electrochemical study of tailored sol-gel thin films as pretreatment prior to organic coating for AZ91 magnesium alloy. Progress in Organic Coatings, 68(4): 347-355.

CAO, F., SONG, G. and ATRENS, A. 2016. Corrosion and passivation of magnesium alloys. Corrosion Science, 111: 835-845.

GRAY J. E. and LUAN B. 2002. Protective coatings on magnesium and its alloys - a critical review. J. Alloy. Compd., 336(1-2): 88-113.

HOUSH, S. and MIKUCKI, B. 1990. Selection and Application of Magnesium and Magnesium Alloys. In: Properties and Selection: Nonferrous Alloys and Special-Purpose Materials. Vol. 2. ASM Handbook. ASM International, pp. 455-479.

LUO, A. A. 2013. Applications: aerospace, automotive and other structural applications of magnesium. In: PEKGULERYUZ, M. KAINER, K. and KAYA, A. (Eds.). Fundamentals of magnesium alloy metallurgy. Philadelphia, PA: Woodhead Publishing.

MORDIKE B. L. and EBERT, T. 2001. Magnesium: properties-applications-potential. Materials Science and Engineering, 302(1): 37-45.

POMMIERS, S., FRAYRET, J., CASTETBON A. and POTIN-GAUTIER M. 2014. Alternative conversioin coatings to chromate for the protection of magnesium alloys. Corrosion Science, 84: 135-146.

PRECIAD, M., BRAVO, P. M. and DARDENAS, D. 2017. Deep cryogenic treatment of HPDC AZ91 magnesium alloys prior to aging and its influence on alloy microstructure and mechanical properties, Journal of Materials Processing Technology, 239: 297-302.

SHAOZHEN, Z., TIANJIAO, L., TINGAN, Z., YINGJU, L. and YUANSHENG, Y. 2017. Effects of Cu addition on the microstructure and mechanical properties of as-cast and heat treated $\mathrm{Mg}$-6Zn-4Al magnesium alloy. Materials Science and Engineering, 689: 203-211.

SINGH, I. B., SINGH, M. and DAS, S. 2015. A comparative corrosion behavior of Mg, AZ31 and AZ91 alloys in 3.5\% NaCl solution. Journal of Magnesium and Alloys, 3(2): 142-148.

VAN PHUONG, N., MOON, S., CHANG, D. and LEE, K. H. 2013. Effect of microstructure on the zinc phosphate conversion coatings on magnesium alloy AZ91. Applied Surface Science, 264: 70-78.

WANG, Y., LIU, G. and FAN, Z. 2006. A new heat treatment procedure for rheo-diecast AZ91D magnesium alloy. Scripta Materialia, 54: 903-908.

WESTENGEN, H., KHALFALLA, Y. and BENYOUNIS, K.Y. 2016. Magnesium Alloys: Thermal Treatment and Thermomechanical Processing. In: Reference Module in Materials Science and Materials Engineering. Elsevier.

YONG, J., DING, C. and QIONG, J. 2012. Effect of cryogenic thermocycling treatment on the structure and properties of magnesium alloy AZ91. Metal Science and Heat Treatment, 53: 589-591. 
ZHAO, M. et al.2006. A chromium-free conversion coating of magnesium alloy by a phosphate-permanganate solution. Surface $\sigma$ Coatings Technology, 200(18-19): 5407-5412.

ZHAO, M., LIU, M., SONG, G. and ATRENS, A. 2008. Influence of the $\beta$-phase morphology on the corrosion of the Mg alloy AZ91. Corrosion Science, 50(7): 1939-1953.

Contact information

Barbora Ševčíková: xcnovakova3@fch.vutbr.cz

Stanislava Fintová: fintova@ipm.cz

Jaromír Wassebauer: wasserbauer@fch.vutbr.cz

Jakub Tkacz:tkacz@fch.vutbr.cz 